\title{
Efficacy of Omeprazole, Tetracycline, and 4 Times Daily Dosing of Amoxicillin in Helicobacter pylori Eradication in Limited Resource Area in Bhutan: A Prospective Randomized Trial (BHUTAN Study)
}

\author{
Ratha-Korn Vilaichone ${ }^{1,2,3 *}$, Natsuda Aumpan ${ }^{1,3}$, Thawee Ratanachu-ek ${ }^{4}$, \\ Pornpen Gumnarai ${ }^{3,5}$, Tomohisa Uchida ${ }^{6}$, Lotay Tshering ${ }^{7}$, Varocha Mahachai ${ }^{8}$, \\ Yoshio Yamaoka ${ }^{9}$
}

\begin{abstract}
Backgrourd: H. pylori-associated gastric cancer is the first cancer-related death in Bhutan. Effective regimen for H. pylori eradication is essential to reduce risk of developing gastric cancer. Clarithromycin is not widely used in this limited resource country. Aim of this study was to evaluate proper regimen and prevalence of antibiotic resistance pattern for $H$. pylori eradication in Bhutan. Methods: Five hundred and forty-six patients underwent gastroscopy during GASTROCAMP between October 2014 and April 2015 in Bhutan and 77 patients were enrolled. Four gastric biopsies were obtained for rapid urease test, histopathology, H. pylori culture with Epsilometer test. All H. pylori-positive patients were randomized to receive either 7-day or 14-day of $500 \mathrm{mg}$ amoxicillin four times daily, $500 \mathrm{mg}$ tetracycline four times daily, and $20 \mathrm{mg}$ omeprazole twice daily. Results: Seventy-seven subjects were enrolled (54 females, 23 males, mean age $=45.4$ years). Of 77 patients, $52(67.5 \%)$ received 7-day regimen while $25(32.5 \%)$ had 14 -day regimen. Prevalence of $H$. pylori was $38.2 \%$. Antibiotic resistance was $80.0 \%$ for metronidazole, $11.1 \%$ for levofloxacin and no resistance seen in amoxicillin, tetracycline and clarithromycin. Overall eradication rates of 7-day and 14-day regimens were $51.9 \%$ and $80.0 \%, \mathrm{p}=0.02$. Female and age $\geq 40$ years had significantly higher eradication rate when receiving 14-day compared to 7 -day regimen $(94.1 \%$ vs. $45.9 \%, \mathrm{OR}=18.82 ; 95 \%$ CI $2.26-157.02, \mathrm{p}=0.0007$ and $86.7 \%$ vs. $50.0 \%$, $\mathrm{OR}=6.50 ; 95 \%$ CI 1.25-33.91, $\mathrm{p}=0.02$, respectively). Conclusions: Fourteen-day regimen might be an acceptable regimen for $H$. pylori eradication in limited resource area such as Bhutan. Female and age $\geq 40$ years should receive longer duration of treatment. This 14-day regimen could at least reduce the risk of developing $H$. pylori-associated diseases especially peptic ulcer with complications and gastric cancer which lead to many deaths in Bhutan.
\end{abstract}

Keywords: Helicobacter pylori eradication- limited resource area- Bhutan

Asian Pac J Cancer Prev, 21 (4), 1109-1114

\section{Introduction}

Helicobacter pylori (H. pylori) is a gram-negative bacterium which colonizes and causes chronic infection of stomach (Dunn et al., 1997). Milder form of $H$. pylori infection is gastric mucosal inflammation or gastritis. However, it can eventually lead to more serious conditions such as gastric mucosa-associated lymphoid tissue (MALT) lymphoma, and gastric cancer, which is the third leading cause of cancer deaths according to global cancer statistics in 2018 (McColl, 2010; Srinarong et al., 2014; Vilaichone et al., 2014; Bray et al., 2018; Vilaichone et al., 2018; Poonyam et al., 2019). Host genetic polymorphisms regulating inflammatory response to $H$. pylori infection, along with bacterial virulence and colonization factors play an important role in the pathogenesis of $H$. pylori-related disease (Amieva and El-Omar, 2008). Therefore, host, bacteria and environment integration are factors exerting influence on distinct clinical outcomes between each location (Kuster et al., 2006; Yamaoka and Graham, 2014). Compared to other regions, Asia has the highest incidence and prevalence of

${ }^{1}$ Gastroenterology Unit, Department of Medicine, Faculty of Medicine, Thammasat University Hospital, ${ }^{2}$ Department of Medicine, Chulabhorn International College of Medicine (CICM), ${ }^{3}$ Digestive diseases Research Center (DRC), ${ }^{5}$ Department of Biochemistry, Faculty of Medicine, Thammasat University, Pathumthani, ${ }^{4}$ Department of Surgery, Rajavithi Hospital, ${ }^{8}$ Gastrointestinal and Liver Center, Bangkok Medical Center, Bangkok, Thailand, ${ }^{6}$ Department of Molecular Pathology, ${ }^{9}$ Department of Environmental and Preventive Medicine, Oita University Faculty of Medicine, Yufu, Japan, ${ }^{7}$ Department of Surgery, Jigme Dorji Wangchuk National Referral Hospital, Thimphu, Bhutan.*For Correspondence:Vilaichone@hotmail.co.th 
gastric cancer accentuating potential health concerns in this area (Rahman et al., 2014).

Kingdom of Bhutan is a landlocked country located in South Asia. Bhutan is bordered by Tibet to its north and west, while India borders its west, east, and south. Considered as one of the countries with the lowest population density, Bhutan has total population of 735,553 per total area of 38,394 square kilometers. The country's geographical features mainly comprise deep valleys and steep mountains with most Himalayan peaks in the north elevated over 7,000 meters above sea level. In this country, cancer is responsible for $10 \%$ of all deaths with gastric cancer being the leading cause of cancer mortality. In Bhutan, stomach cancer had the highest incidence of $20.7 \%$, and mortality rate of $23.9 \%$ making it the most important disease to focus on (World Health Organization, 2018). Moreover, Bhutan's age-standardized mortality rate of gastric cancer was relatively high as 18.9 per 100,000 compared to 8.2 of global range (International Agency for Research on Cancer, 2018). Persistent H. pylori infection is a major risk factor of developing non-cardia gastric cancer (Plummer et al., 2015). The overall prevalence of H. pylori infection in Bhutan population was extremely high as $73.4 \%$ which could contribute to high gastric cancer incidence in Bhutan (Vilaichone et al., 2013). Therefore, effective $H$. pylori eradication should be taken into consideration for gastric cancer prevention (Mahachai et al., 2016). However, the information about eradication therapy in Bhutan is still lacking.

Until now, the issue about $H$. pylori treatment in Bhutan has not been addressed before. The purpose of this study was to evaluate proper duration of antibiotic treatment for $H$. pylori-infected patients in order to implement the most effective regimen for $H$. pylori eradication in Bhutan population. In this prospective randomized trial, we used triple therapy for 7 or 14 days to eradicate the bacteria. The antimicrobial susceptibility testing was also performed to determine the distribution of antibiotic resistant $H$. pylori strains in Bhutan.

\section{Materials and Methods}

\section{Patients}

Five hundred and forty-six patients underwent upper GI endoscopy during GASTROCAMP between October 2014 and April 2015 in Bumthang and Haa provinces, Bhutan. A total of 77 patients with dyspepsia residing in the cities named Bumthang and Haa were enrolled in this prospective study. There were 23 males and 54 females with the mean age of 45.4 years. All patients included in this study underwent upper GI endoscopy and were diagnosed with non-ulcer dyspepsia which was defined as normal or mild gastritis. We excluded patients receiving $\mathrm{H} 2$ receptor antagonists, proton pump inhibitor (PPI), bismuth compound, and antimicrobial agents within 4 weeks prior to the study, using NSAIDs and anticoagulant, having history of stomach surgery, or having significant comorbidities such as renal failure, advanced cirrhosis, advanced-stage cancer, or cardiac arrhythmia. Special population such as immunocompromised hosts, pregnant women, or breastfeeding women were also excluded.
Informed consent was obtained from volunteers at the beginning of the study.

\section{Sample collection}

All 77 Bhutanese patients in the study underwent upper GI endoscopy and 4 gastric biopsies were obtained for rapid urease test, histopathology, $H$. pylori culture with antimicrobial susceptibility tests (Epsilometer test).

\section{Rapid urease test}

The test label was peeled off and an antral biopsy was placed in the center of the test well. Then, the test label was resealed and left at room temperature for 60 minutes. If there were $H$. pylori in the tissue specimen, the bacterial urease would convert urea to ammonia and consequently change the $\mathrm{pH}$ indicator color from yellow to pink. In this study, all patients with positive rapid urease test were given triple therapy.

\section{Histopathology}

The gastric biopsies were processed in the embedding and cutting procedure. They were later stained with hematoxylin and eosin. A positive H. pylori biopsy sample was defined as a sample with curved rod-shaped bacteria.

\section{H. pylori culture}

The Eppendorf tubes containing transport media were used for antral biopsy collection. One antral biopsy was minced and mixed in the broth and then streaked on a Mueller Hinton - Agar medium using a sterile heated wire loop. The medium was then put in the candle jar and incubated at $37^{\circ} \mathrm{C}$ in microaerophilic condition for 3 to 5 days. Colors of $H$. pylori colonies ranged from translucent to pale grey on blood agar. For H. pylori detection, gram staining was used and showed small curved gram-negative, rod-shaped bacteria. The biochemical tests including oxidase, catalase, and urease tests were all positive for $H$. pylori.

\section{Antimicrobial susceptibility testing}

The Epsilometer test (E-test) provides information about antimicrobial susceptibility and determines the minimum inhibitory concentrations (MICs) of antibiotics including amoxicillin (AMX), clarithromycin (CLR), metronidazole (MNZ), tetracycline (TET), and levofloxacin (LVX). The bacteria were inoculated on the plates on which E-test strips with antibacterial agents were placed. Three to five days later, an ellipse became visible. The MIC was defined by the point of intersection between an ellipse and the MIC reading scale which indicated the lowest concentration of antibiotics that was able to inhibit visible bacterial growth. Resistant strains were considered when MIC values were $\geq 0.25 \mu \mathrm{g} / \mathrm{mL}$ for $\mathrm{AMX}, \geq 1 \mu \mathrm{g} / \mathrm{mL}$ for CLR,$\geq 8 \mu \mathrm{g} / \mathrm{mL}$ for $\mathrm{MNZ}, \geq 1$ $\mu \mathrm{g} / \mathrm{mL}$ for $\mathrm{LVX}$, and $\geq 4 \mu \mathrm{g} / \mathrm{mL}$ for TET (Mégraud $\mathrm{F}$ and Lehours, 2007).

\section{Therapeutic regimens}

All patients with positive rapid urease test were randomized into 2 groups using a computer-generated list of random numbers to receive either 7-day or 14-day of 
$500 \mathrm{mg}$ amoxicillin four times daily, $500 \mathrm{mg}$ tetracycline four times daily, and $20 \mathrm{mg}$ omeprazole twice daily.

\section{Post-therapy follow-up}

H. pylori eradication was confirmed by using $13 \mathrm{C}$ - urea breath test (13C-UBT) at 4 weeks after completing a course of the triple therapy. 13C-UBT is a non-invasive test determining treatment success by detection of labeled $\mathrm{CO}_{2}$ exhaled in a breath sample. If the result showed negative $13 \mathrm{C}-\mathrm{UBT}$ then the patient was considered achieving successful $H$. pylori eradication (Tongtawee et al., 2014).

\section{Statistical analysis}

The statistical analysis was performed by using SPSS version 22 (SPSS Inc., Chicago, IL, USA). The demographic data were analysed by unpaired t-test, Fisher's exact test, and Chi-square test where appropriate. Statistical significance was defined as a two-tailed p-value cut point of less than 0.05 .

\section{Results}

Total of 77 patients were enrolled in the study. The mean age of all patients was 45.4 years with female preponderance $(70.1 \%)$. Of 77 patients, $52(67.5 \%)$ received 7-day regimen while $25(32.5 \%)$ had 14-day regimen. The majority of patients came from Haa $(74.0 \%)$, the district in the west of Bhutan while the rest were from Bumthang $(26.0 \%)$, the district in central region. Every patient in the study had $H$. pylori infection identified by positive rapid urease test and was given either 7-day or 14-day triple therapy. The endoscopic findings of all patients were gastritis. Demographic data including gender, age group, and the study location were demonstrated in Table 1.

The H. pylori eradication rate of 7-day triple therapy was significantly lower than that of 14-day regimen $(51.9 \%$ vs. $80.0 \%, p=0.02)$. Classified by gender, 37 of all 54 females received 7-day regimen while 17 received 14-day treatment. However, males in both groups showed relatively low eradication rate with only $66.7 \%$ and $50 \%$ in 7-day and 14-day triple therapy, respectively. When categorized into two age groups, the successful eradication was observed remarkably higher in patients older than 40 years receiving 14-day therapy compared to 7 -day treatment $(86.7 \%$ vs. $50.0 \%$; $=0.02)$. The younger-than-40-year age group also demonstrated the increase in eradication rate from $50 \%$ in 7 -day therapy to $70 \%$ in 14 -day therapy but could not reach statistical significance $(p=0.44)$. Patients receiving 14 -day therapy were more likely to have successful eradication than the group receiving 7-day regimen $(\mathrm{OR}=3.70 ; 95 \% \mathrm{CI} 1.21$ $11.36, p=0.02)$. Female and age $\geq 40$ years subgroup also demonstrated significantly higher eradication rate when receiving 14-day compared to 7-day regimen (94.1\% vs. $45.9 \%, \mathrm{OR}=18.82 ; 95 \%$ CI 2.26-157.02, $\mathrm{p}=0.0007$ and $86.7 \%$ vs. $50.0 \%, \mathrm{OR}=6.50 ; 95 \%$ CI $1.25-33.91, \mathrm{p}=0.02$, respectively). The eradication rate and factors affecting on the treatment outcome were shown in Table 2. The difference of eradication rate classified by gender and age group was demonstrated in Figure 1 and 2, respectively.

The gastric biopsies of patients with positive urease test were sent for $H$. pylori culture. Forty-five patients had

Table 1. Demographic Data

\begin{tabular}{lcccc}
\hline Demography & Total $(\mathrm{n}=77)$ & 7-day regimen $(\mathrm{n}=52)$ & 14-day regimen $(\mathrm{n}=25)$ & $P$-value \\
\hline Gender & & & & \\
$\quad$ Men & $23(29.9 \%)$ & $15(28.8 \%)$ & $8(32.0 \%)$ & 0.78 \\
Women & $54(70.1 \%)$ & $37(71.2 \%)$ & $17(68.0 \%)$ & 0.78 \\
Mean age \pm SD (years) & $45.4 \pm 12.7$ & $45.8 \pm 13.8$ & $44.7 \pm 10.2$ & 0.74 \\
$\quad$ Range & $17-75$ & $17-75$ & $30-61$ & 1 \\
$<40$ years & $30(40.0 \%)$ & $20(40.0 \%)$ & $10(40.0 \%)$ & 1 \\
$\geq 40$ years & $45(60.0 \%)$ & $30(60.0 \%)$ & $15(60.0 \%)$ & 1 \\
\hline
\end{tabular}

Eradication rate

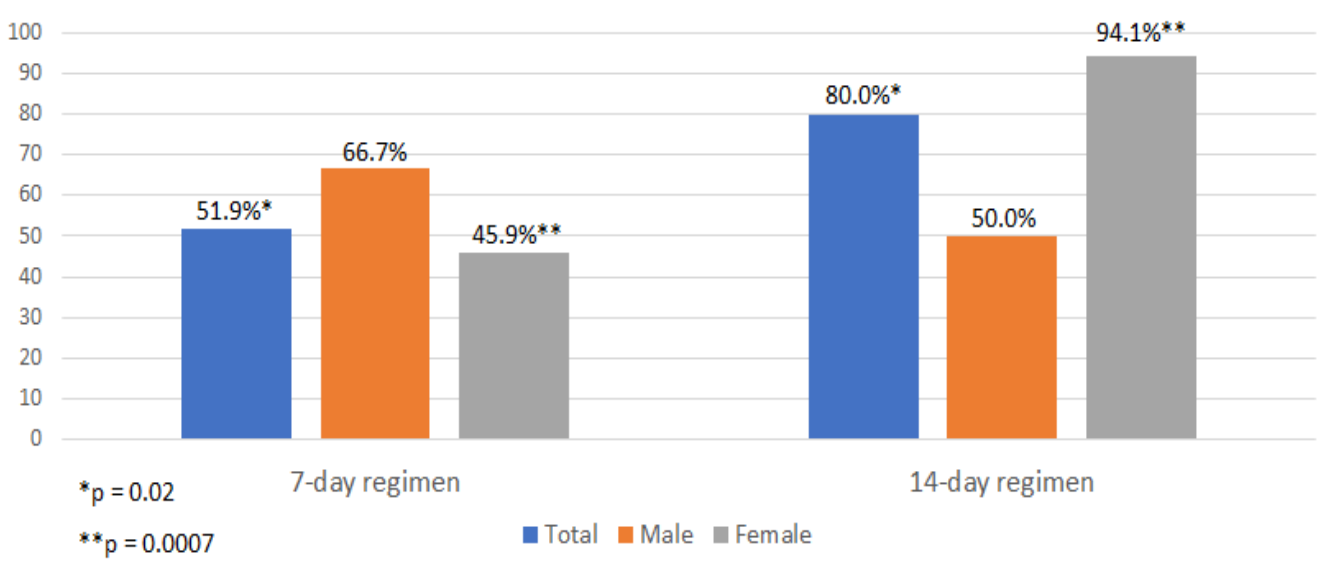

Figure 1. Effect of Genders on H. pylori Eradication Rate 
Eradication rate

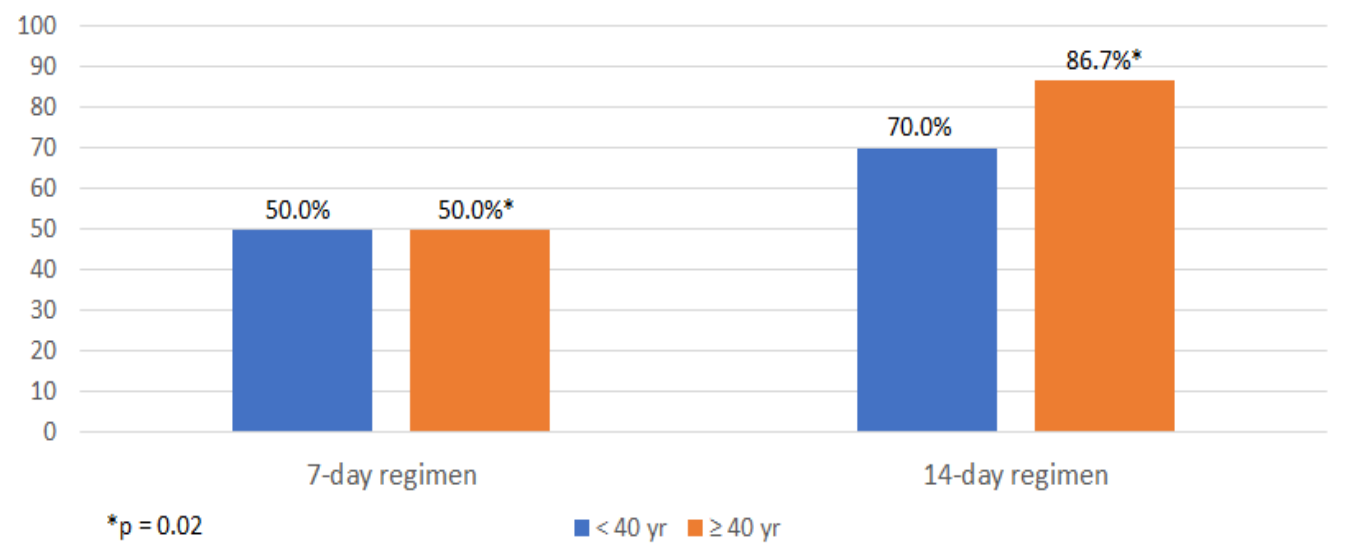

Figure 2. Effect of Age Groups on H. pylori Eradication Rate

Table 2. Effect of Clinical Factors on $H$. pylori Eradication Rate

\begin{tabular}{lccc}
\hline Factors & 7-day regimen & 14-day regimen & $\mathrm{p}$-value \\
\hline Total & 27/52(51.9\%) & $20 / 25(80.0 \%)$ & 0.02 \\
Gender & & & \\
$\quad$ Men & $10 / 15(66.7 \%)$ & $4 / 8(50.0 \%)$ & 0.66 \\
$\quad$ Women & $17 / 37(45.9 \%)$ & $16 / 17(94.1 \%)$ & 0.0007 \\
Age & & & \\
$\quad<40$ years & $10 / 20(50.0 \%)$ & $7 / 10(70.0 \%)$ & 0.44 \\
$\quad \geq 40$ years & $15 / 30(50.0 \%)$ & $13 / 15(86.7 \%)$ & 0.02 \\
\hline
\end{tabular}

positive culture $(78.9 \%)$. Thirty-six patients $(80.0 \%)$ in the study mainly had metronidazole-resistant strains. Five patients $(11.1 \%)$ were infected with strains resistant to metronidazole and levofloxacin. Interestingly, no resistance seen in amoxicillin, tetracycline and clarithromycin. There was no difference of antibiotic-resistant strains between genders. The antibiotic susceptibility testing was demonstrated in Table 3.

\section{Discussion}

Bhutan is a small peaceful sovereign state in South Asia located on the eastern edge of the Himalayas. Its landscape ranges from tropical plains in the south to Himalayan forests and mountains in the north. Although the country has been opened to foreigners since 1974, there are still low numbers of international tourists entering the kingdom. In medical field, there has also been a small number of clinical research conducted recently. As cancer incidence in Bhutan has been rising, Bhutan cancer society was founded in 2015 in order to raise awareness of cancer prevention and research. Gastric cancer is the most prevalent cancer in Bhutan and often diagnosed at an advanced stage (Dendup et al., 2015). Chronic H. pylori infection was proved to be associated with gastric cancer in many studies (Parsonnet et al., 1991; Vilaichone et al., 2006; Karami et al., 2013). The previous study revealed that the overall prevalence of $H$. pylori infection in Bhutanese population was as high as $73.4 \%$ and the rate was even higher in rural areas (Vilaichone et al., 2013). Our study was conducted in rural districts named Haa and Bumthang in which we supposed that the prevalence would be as high as $80-90 \%$ as mentioned in two previous studies (Vilaichone et al., 2013; Dorji et al., 2014). The study population was predominantly female $(70.1 \%)$ and the mean age was 45.4 years which were slightly higher than proportion of females $(57.5 \%)$ and the mean age (39.6 years) in the prior study (Vilaichone et al., 2013). In our study, all patients with positive urease test were prescribed triple therapy composed of amoxicillin, tetracycline, and omeprazole and scheduled a follow-up visit. Tetracycline was used instead of clarithromycin because tetracycline had a local stock while clarithromycin was not available and had to be imported from India.

Our study demonstrated that 14-day triple therapy had significantly higher $H$. pylori eradication rate $(80 \%)$ than 7 -day regimen $(51.9 \%)$. In concordance with previous studies and systematic reviews, the duration of triple therapy should be extended to 14 days to improve eradication rate (Yuan et al., 2013; Mahachai et al., 2016). The higher eradication rate of 14-day regimen was also

Table 3. Antibiotic Susceptibility Testing

\begin{tabular}{lcccc}
\hline Antibiotics & Total $(\mathrm{n}=45)$ & Male $(\mathrm{n}=19)$ & Female $(\mathrm{n}=26)$ & $P$-value \\
\hline Antibiotic resistance & & & & \\
-Amoxicillin (AMX) & 0 & 0 & 0 & - \\
-Clarithromycin (CLR) & 0 & 0 & 0 & - \\
-Metronidazole (MNZ) & $36(80.0 \%)$ & $15(78.9 \%)$ & $21(80.8 \%)$ & 1.00 \\
-Tetracycline (TET) & 0 & 0 & 0 & - \\
-Levofloxacin (LVX) & $5(11.1 \%)$ & $2(10.5 \%)$ & $3(11.5 \%)$ & 1.00 \\
-MNZ and LVX & $5(11.1 \%)$ & $2(10.5 \%)$ & $3(11.5 \%)$ & 1.00 \\
\hline
\end{tabular}


significant in female than male subgroup which might be explained by more severe mucosal inflammation and activity resulting from different level of intramucosal cytokines and genetic expression in men (Kato et al., 2004). Classified by age group, the $H$. pylori eradication rate in older age group was superior to that of the younger generation and significantly improved by using 14-day triple therapy. The previous study in Japan revealed that people in older age group were inclined to achieve more successful eradication because of more prevalent gastric atrophy and acid hyposecretion leading to superior antibiotic response (Mamori et al., 2010). Apart from host factors, bacterial factors such as virulence factor and antibiotic resistance also play important roles in $H$. pylori treatment.

The antimicrobial susceptibility of Bhutanese patients in this study exhibited the strains mostly resistant to metronidazole $(80.0 \%)$. The metronidazole-resistant rate was approximately the same as $82.9 \%$ of previous study conducted in districts of Thimphu, Punaka, and Wangdue of Bhutan (Vilaichone et al., 2013). However, the multidrug-resistant strains (11.1\%) were more frequently found in our study than our prior report $(2.7 \%$ ) (Vilaichone et al., 2013). Multidrug-resistant strains isolated in both studies showed resistance to the same types of antibiotics which were metronidazole and fluoroquinolones. Rising numbers of multidrug-resistant strains may be due to increasing antibiotic use. Bhutan's communicable, maternal, perinatal, and nutritional conditions were responsible for $21 \%$ of premature deaths which were three times higher than the rate of developed countries. Metronidazole is commonly used for treatment of diarrheal diseases, gynecologic and periodontal infections, whereas levofloxacin is generally used for lower respiratory tract infection. Both gastrointestinal and respiratory infection are major problems in the country and can probably cause an increasing rate of the two most common antibiotic resistance in Bhutan. It can be concluded that metronidazole-based triple therapy should not be used as first-line regimen in the country with high primary metronidazole resistance (Katelaris, 2009). Nevertheless, the previous study in Thailand showed that bismuth-based quadruple therapy containing metronidazole could still be used despite high metronidazole resistance (Vilaichone et al., 2015). Moreover, levofloxacin-based regimen may also have reduced efficacy and cannot be used as a substitute regarding the growing resistant strains to fluoroquinolone (Perna et al., 2007). Since no resistance to amoxicillin, tetracycline, and clarithromycin was noted in our study, these antibiotics can still be used in the firstline treatment for H. pylori in Bhutan.

Gastric cancer ranked highest in prevalence, incidence and cancer mortality in Bhutan. Our study suggested that 14-day omeprazole, tetracycline, and 4 times daily dosing of amoxicillin might be an acceptable regimen for $H$. pylori eradication in limited resource area such as Bhutan. This regimen could reduce the risk of developing H. pylori-associated diseases especially peptic ulcer with complications and gastric cancer leading to many deaths in Bhutan.

\section{Acknowledgments}

This study was supported by Bualuang ASEAN Chair Professorship at Thammasat University, and Digestive Diseases Research Center (DRC), Thammasat University, Thailand

\section{References}

Amieva MR, El-Omar EM (2008). Host-bacterial interactions in Helicobacter pylori infection. Gastroenterology, 134, 306-23.

Bray F, Ferlay J, Soerjomataram I, et al (2018). Global cancer statistics 2018: GLOBOCAN estimates of incidence and mortality worldwide for 36 cancers in 185 countries. CA Cancer J Clin, 68, 394-424.

Dendup T, Richter JM, Yamaoka Y, et al (2015). Geographical distribution of the incidence of gastric cancer in Bhutan. World J Gastroenterol, 21, 10883-9.

Dorji D, Dendup T, Malaty HM, et al (2014). Epidemiology of Helicobacter pylori in Bhutan: the role of environment and Geographic location. Helicobacter, 19, 69-73.

Dunn BE, Cohen H, Blaser MJ (1997). Helicobacter pylori. Clin Microbiol Rev, 10, 720-41.

International Agency for Research on Cancer (2018). Bhutan source: Globocan 2018.

Katelaris PH (2009). Helicobacter pylori: antibiotic resistance and treatment options. J Gastroenterol Hepatol, 24, 1155-7.

Kato S, Matsukura N, Togashi A, et al (2004). Sex differences in mucosal response to Helicobacter pylori infection in the stomach and variations in interleukin-8, COX-2 and trefoil factor family 1 gene expression. Aliment Pharmaco Ther, 20, 17-24.

Karami N, Talebkhan Y, Saberi S, et al (2013). Seroreactivity to Helicobacter pylori antigens as a risk indicator of gastric cancer. Asian Pac J Cancer Prev, 14, 1813-7.

Kuster JG, van Vilet AHM, Kuipers EJ (2006). Pathogenesis of Helicobacter pylori Infection. Clin Microbiol Rev, 19, 449-90.

Mahachai V, Vilaichone RK, Pittayanon R, et al (2016). Thailand consensus on Helicobacter pylori treatment 2015. Asian Pac J Cancer Prev, 17, 2351-60.

Mamori S, Higashida A, Kawara F, et al (2010). Age-dependent eradication of Helicobacter pylori in Japanese patients. World $J$ Gastroenterol, 16, 4176-9.

McColl KE (2010). Helicobacter pylori Infection. N Engl J Med, 362, 1597-1604.

Mégraud F, Lehours P (2007). Helicobacter pylori detection and antimicrobial susceptibility testing. Clin Microbiol Rev, 20, 280-322.

Parsonnet J, Friedman GD, Vandersteen DP, et al (1991). Helicobacter pylori infection and the risk of gastric carcinoma. N Engl J Med, 325, 1127-31.

Perna F, Zullo A, Ricci C, et al (2007). Levofloxacin-based triple therapy for Helicobacter pylori re-treatment: role of bacterial resistance. Dig Liver Dis, 39, 1001-5.

Plummer M, Franceschi S, Vignat J, et al (2015). Global burden of gastric cancer attributable to Helicobacter pylori. Int $J$ Cancer, 136, 487-90.

Poonyam P, Chotivitayatarakorn P, Vilaichone RK (2019). High effective of 14-day high-dose PPI- Bismuthcontaining quadruple therapy with probiotics supplement for Helicobacter Pylori eradication: A double blinded-randomized placebo-controlled study. Asian Pac J Cancer Prev, 20, 2859-64.

Rahman R, Asombang AW, Ibdah JA (2014). Characteristics of gastric cancer in Asia. World J Gastroenterol, 20, 4483-90. Asian Pacific Journal of Cancer Prevention, Vol $21 \quad 1113$ 
Srinarong C, Siramolpiwat S, Wongcha-um A, et al (2014). Improved eradication rate of standard triple therapy by adding bismuth and probiotic supplement for Helicobacter pylori treatment in Thailand. Asian Pac J Cancer Prev, 15, 9909-13.

Tongtawee T, Kaewpitoon S, Kaewpitoon N, et al (2016). Diagnosis of Helicobacter pylori infection. Asian Pac J Cancer Prev, 17, 1631-5.

Vilaichone RK, Mahachai V, Graham DY (2006). Helicobacter pylori diagnosis and management. Gastroenterol Clin North Am, 35, 229-47.

Vilaichone RK, Mahachai V, Shiota S, et al (2013). Extremely high prevalence of Helicobacter pylori infection in Bhutan. World J Gastroenterol, 18, 2806-10.

Vilaichone RK, Panarat W, Aekpongpaisit S, et al (2014). Clinical characteristics and Helicobacter pylori status of gastric cancer in Thailand. Asian Pac J Cancer Prev, 15, 9005-8.

Vilaichone RK, Prapitpaiboon H, Gamnarai P, et al (2015). Seven-day bismuth-based quadruple therapy as an initial treatment for Helicobacter pylori infection in a high metronidazole resistant area. Asian Pac J Cancer Prev, 16, 6089-92

Vilaichone RK, Quach DT, Yamaoka Y, et al (2018). Prevalence and pattern of antibiotic resistant strains of Helicobacter pylori infection in ASEAN. Asian Pac J Cancer Prev, 19, 1411-3.

Vilaichone RK, Yamaoka Y, Shiota S, et al (2013). Antibiotics resistance rate of Helicobacter pylori in Bhutan. World $J$ Gastroenterol, 19, 5508-12.

World Health Organization (2018). Noncommunicable diseases country profiles 2018, 47.

Yamaoka Y, Graham DY (2014). Helicobacter pylori virulence and cancer pathogenesis. Future Oncol, 10, 1487-1500.

Yuan Y, Ford AC, Khan KJ, et al (2013). Optimum duration of regimens for Helicobacter pylori eradication. Cochrane Database Syst Rev, 13, 1-277.

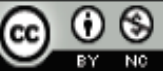

This work is licensed under a Creative Commons AttributionNon Commercial 4.0 International License. 